\title{
Wendy Olsen
}

\section{Stereotypical and Traditional Views About the Gender Division of Labour in Indian Labour Markets}

\section{BACKGROUND}

In this paper I attempt to apply several lessons from critical realism to statistical analysis, and in particular to cross-sectional survey analysis methodology. My findings, including a novel re-interpretation of the two main variants of factor analysis, can be applied to market research, voting surveys, evaluations of all kinds using questionnaires, interview-based survey data, creation of tabular data from documents or court cases or patient records, etc. The research reported on here is thus grounded in my present objective of developing a novel pedagogy of statistical survey methodology, suitable for beginners as well as experts. Whilst this new pedagogy is critical realist, it is best labelled critical social statistics since it has its roots in critical social science more broadly (as represented by the work of Brian Fay, Lee Harvey, Sylvia Walby, and Anne Oakley, for instance).

Critical realism has two origins (ontological and epistemological), and a brief review may be desirable. Realism, a current in philosophy of social science, is an ontology (theory of existence) that claims the real world exists; that it includes the real, and the actual, and - as a subset - the empirical evidence which can be created. This world is partly social and it has a layered, or stratified, structure including bodies, people, families, nations, and the global or international community. At each level, we can discern emergent properties that cannot be seen or measured (or even conceived of) at lower levels. Some of these properties are ignored if we stay at too high a level. Empirical research can explore several levels.

Positivists, by contrast, lack a complex ontology, and have stuck to epistemology instead. They tend to judge the truth of claims by testing them with empirical evidence. This sets no limits to what can count as empirical evidence and regrettably positivists have often examined a single, isolated unit of analysis such as the firm or the person. Positivists, often seeking constant conjunctions of events recorded in data, have shown an excessive individualism (especially in economics and psychology), caused confusion about the household in economics, and made simplistic self-verifying models in market research and social policy. Realists, by contrast, recommend assuming that good explanations will be multi-causal and never imply that one simple model explains everything. As a result, say critical realists, descriptions of society can almost always be improved upon.

The epistemological claims of realists rest on comparing claims with evidence that can be gathered, and then trying to work out what must exist in order for the records of events to have been made. Realists do not assume that their sense perceptions exhaust the social or physical world.
There are things we don't know about and there are experiences which belie the underlying ('intransitive') real world, especially the past. Ideology and masking are seen as being possible in critical realism. Critical social scientists argue that we can also disagree profoundly about how to describe or explain social phenomena. The label 'critical social scientists' includes many feminists, some social policy analysts, most marxists and even to some extent the new 'stake-holder' viewpoints - used both in development studies and in social democratic analyses of civil society in Western societies.

Critical realism thus provides a philosophical basis for a school of thought that cuts across several social science disciplines. Andrew Sayer (1992) was, as far as I know, the first academic to write a 'methods' textbook based on critical realism. In that book we find a lot of stress on analytical methods, i.e., on how to think about society better.

Thus critical realism has two elements: critique; and realism. Critique includes critiques of data and social theories, as well as critiques of the society itself. Under the critical microscope, mere descriptions of society are not enough; we should go beyond that to asking what social problems we can work on, what should be changed, what is good about social phenomena. The realist element in critical realism takes descriptive interpretation further, arguing that the way we conceive of society can influence society itself. Social structures, for example, are not ahistorical but very much grounded in current ways of talking about social structures. Realism allows a place for social structures and institutions which, it says, can have 'emergent properties' beyond the properties of the people or things that compose them. The world is layered and it is complicated. Realism is a philosophy of social science that admits the great complexity of the social world. Most importantly, though, realists argue and assume that the world exists in part independently of our research on it. It will go on existing even when we are not studying it. The world resists our efforts to make inaccurate statements about it.

In this paper I will explore one particular aspect of the agenda for research that is laid out above. I set myself the task of exploring factor analysis, but the results showed me that factor analysis is intrinsically closely related to regression analysis and to the question of the unit of analysis. It is possible to conceive of a mapping between variables and social things underlying them (section II). The mapping approach helps researchers to focus on ontological questions whatever their specific research focus. I then provide a case study from India (section III), showing by exemplar that exploratory factor analysis 
implies a many-to-many mapping, whereas confirmatory factor analysis implies a much more strict many-to-one mapping between variables and things. Finally, in section IV I review the way my mapping approach, and critical realism generally, creates a need for a review and reassessment of algorithms for doing regression and factor analysis. My conclusions, presented in section $\mathrm{V}$, are centred around a critique of the hermetic seal around survey data that is made into a fetish by some social scientists. I label such an approach empiricist, referring to the desire to ground truths in a single representative data set rather than recognising the temporary, transitive, and tentative nature of claims based upon data. I then provide a linkage between this paper and the debate about triangulation.

\section{CONCEPTUALISING OPERATIONALISATION}

One can conceive of 'variables' as recordable incidences of events which are taken to represent real things. Variants on the mapping between variables and things are numerous. (1) Economists often assume a one-to-one mapping is acceptable, such that variables represent consumption, interest rates, etc. perfectly. (2) Social scientists tend to admit that one variable may confusedly represent two or more things at once, and allow for this with interaction effects or a conceptual discussion. For instance, consumption data reflect both 'household' purchasing decisions and 'personal' purchasing decisions. (3) Social statisticians are also aware that one often gets several variables representing one thing; this many-to-one mapping contrasts with the previous case of a one-to-several mapping. Creating an index by adding up several scales is one example of the many-to-one relation. Latent variable analysis is another, and psychologists frequently use this technique to get multi-dimensional measures of complex real things. (4) If the relation is many-to-many, then we allow for each variable to simultaneously reflect several social things. This last possibility seems most likely, given the complexity of the real world compared with the simplicity of survey data sets. Further mapping relations can be set out once causal mechanisms (which are relations between things) are allowed to have a variable representing them. Similarly, complexity arises if structural relations between things is allowed as another 'thing'. Hence the term 'social object', which plays an important role in critical realist philosophy, has a number of possible types of specific referents in survey statistics. The four basic variants on the variables-to-things mapping represent different moments in the process of analysis of survey data. Future research can expand this analysis to time-series data, but at present I consider only cross-sectional measurement.

In doing social statistics positing a mapping between variables and things, sleight of hand is always used to ignore some things whilst stressing others. The hidden things become more obvious once a causal model is seen as overlapping with a complex way of measuring the characteristics of a complex thing. The complexity of real causation in open systems is not shown. Mathematical models are necessarily closed systems, whereas the social world is always an open system.

\section{A Case Study Using Factor Analysis And REGRESSION ANALYSIS}

In this section I present a pilot factor analysis of microdata on attitudes. I have been exploring change in stereotypes about jobs and other forms of employment relations. My initial pilot study in south India revealed cultural beliefs varying across castes and social class but not by the gender of the respondent. Attitudes did vary by age of respondent, but with just 154 respondents in the random sample, further work will have to be done to examine this age effect in more detail, including its curvature. Data from two additional groups of respondents outside of the random sample showed that groups of people who have been subject to particular historical events hold very different views not conforming to the cultural standard of their respective social classes. This clear finding from the field research is not based on random samples but challenges the supposed 'universality' so often presumed for random samples, no matter how small (Olsen, 1992).

Factor analysis is meant to reduce the multi-collinearity in sets of variables, such as these attitude variables, and is often used in ad hoc ways. Textbooks offer epistemologically ungrounded advice about how to decide among specific factor analysis techniques. In the classic volume which places factor analysis within the general rubric of structural equation models, Loehlin states that 'in exploratory factor analysis we do not begin with a specific model, only with rather general specifications about what kind of a model we are looking for. We must then find the model as well as estimate the values of its paths and correlations' (1992: 134, emphasis added). However Loehlin then goes on to restrict the use of exploratory factor analysis to situations in which a latent variable is potentially measured by (related to) a range of variables which were operationalised. In his view, and in that of Bryman and Cramer (1997), it is best to undertake the factor analysis before beginning a causal analysis. The resulting factors may be utilised in a follow-up regression, but the variables allowed into factor analysis are supposed to be causally independent of each other.

Confirmatory factor analysis, by comparison, uses a set of measured variables explicitly to test whether there is evidence for mutually rising-and-falling values across the data set, which is said to support the a priori claim that the variables tap into an unmeasured thing, such as a broad attitude orientation or a set of social class alignments. In this section I will focus on an exploratory factor analysis rather than the above confirmatory factor analysis option. For the kind of pilot survey I conducted, exploratory factor analysis seems more appropriate.

In either case, however, qualitative investigation prior to the survey is what guides the formation of an initial question bank. Qualitative analysis of comments on the survey can guide the formation of factors or the creation of suitable latent-variable names, recognising the researcher's powerful position as a labeller at this stage.

In the policy arena of micro-enterprise and small business, which is often related to gender and which has become an actively researched area in recent years, the performance of 
the firm and the satisfaction of the proprietor are two areas suitable for latent variable analysis. Performance and satisfaction are also the subject of purely qualitative research by Wheelock and Baines (1998) who strongly contrast a traditional approach to the gender division of labour with newer, untraditional labouring roles. Wheelock and Baines did not specify their conception of 'traditional' labour roles in as much detail as would be needed for a detailed questionnaire survey. Ehlers and Main (1998) also examined gender and micro-enterprise, introducing the concept of the 'pink collar sector' as a labour market segment continually re constructed (whilst changing in its occupations) by men and women who share gender stereotypes that are restrictive for women in public and which allocate most household work to women. Ehlers and Main did not conduct survey research but instead offered a review article. All these authors have strong conceptual frameworks that shape their data collection. They have used triangulation rather than pure survey research. The case study developed below is aimed at the proposition that a merger of triangulation and survey-based statistics can be achieved. A variety of other examples arise in development studies research.

However I turn now to stereotypes of what jobs are suitable for men and women. This topic is of interest across the globe, but I am at present interested in analysing one pilot data set with a view to proposing a comparative study in three countries. One might, for instance, want to analyse several different sets of attitudes concerning:

- whether women and men should enter paid-labour markets or not;

- whether women are worse at technical or spatial skills than men;

- whether women need to have less spatial movement than men away from home;

- whether men have a strength or agility advantage over women;

- which people are presumed to be suitable for going into business or micro-enterprise;

- whether specific forms of labour contract are more suitable for men or women: piecework; contract labour gangs; casual daily labour; full time employment on contract; part time employment on contract.

- whether women or men are seen as more appropriate for doing different forms of agriculture - food, cash crops, animals.

At three questions each, there would be a huge bank of opinion here even based on the kind of a priori hypothesising hinted at above. However the above bullet points arose ex post after the pilot survey, which I now describe.

\section{Case study introduction: the data}

My doctoral research involved the selection of 75 households from a carefully constructed enumeration census of 1200 households in one area, consisting of about twelve hamlets, in southern Andhra Pradesh. The area lies in an upland region which has unimodal rainfall and well/ canal/ reservoir irrigation for the production of groundnut, rice and other crops including various cash crops. The original research focused upon money lending and the terms of borrowing in 1986-1987 (Olsen, 1996). In 1999 I selected 80 households at random from the original 1200 households enumerated. This sample is not co-extant with the 75 households originally studied because the latter were clustered in two village gramams containing just ten of the original twelve hamlets. In general, the present pilot study is more representative of the overall survey area, including its hinterland, whereas the doctoral research was more representative of the area alongside roads plus the associated harijan hamlets on connected paths. For background analyses of the hinterland labour markets compared with the more central villages, see DaCorta and Venkateswarlu, 1999. For details of hamlet-wise segmentation of the main-village labour markets, see Olsen and DaCorta, 1990. For a summary of the doctoral research see Olsen, 1993.

In 1999 Rangaswamy, my primary research assistant during the doctoral research, revisited the area to catch three persons per household and verbally conduct an interview based upon the questionnaire. ' Rangaswamy showed respondents a set of faces (ranging from big smiles to big frowns) representing responses on a Likert scale to a number of attitude questions about the involvement of a young person from their household in the labour market. For literate respondents the corresponding numbers and phrases, both in Telugu and in English, could be seen below the faces. Rangaswamy also wrote down a summary of their comments on each block of questions, usually in English. In the school for teenage boys where Rangaswamy now teaches, he also conducted the same survey as a self-completion questionnaire and the boys wrote qualitative comments in Telugu. The qualitative data will be analysed elsewhere. Davuluri Venkateswarlu conducted a similar survey with 55 additional respondents of various ages in northern Andhra Pradesh.

Rangaswamy deliberately chose people from a range of age groups, both male and female, depending upon their availability within households. In the study area the mean household size is five, so choosing three people per household often meant choosing all the people over 16 living there.

\section{Case study methodology: possibilities for regression and factor analysis}

Regression analysis has already been undertaken using an index of gender-stereotyped attitudes as the dependent variable alongside a limited range of independent variables, including age, caste, social class and gender of the respondent.

However the main focus of my interest was not the causal determination of attitudes to labouring, but rather the range of attitudes, the shape of their distributions, and the way that attitudes to young people going out in public might intermesh with attitudes to young people's own aspirations in the world of employment (and their parents' and grandparents' aspirations on their behalf). However the causal analysis of an index of stereotypicality convinced me that it would be wrong to generalise about attitudes across the survey population: rather there is 
considerable variation across socio-demographic groups, excepting genders. I was wary of factor analysis because of its insistence on including all the cases in the measurement of correlations when I knew that some stereotypes only applied within a case, within a social class, or to a particular gender within a class/ caste. However I have proceeded with factor analysis as a way to explore a complex data set containing in all 300 rows and 73 columns.

\section{Case study results: descriptive statistics}

The means of the Likert scales differed significantly using a Chi-squared test across the three study areas for every variable. It is important to recognise that the apparent universality and generalisability of the results from the random sampling in southern Andhra Pradesh can and should be challenged by realists.

The average Likert scale values differed substantially for all the attitude variables in the questionnaire, with femalestereotyped jobs getting a high rating for young women to do and a low rating for young men to do, and vice versa (see original paper, Table 1, for details; available via the IACR web site). The survey showed that there were clear age and class differences in the levels chosen on the Likert Scales, but there were very few gender differences even within a social class or within an age group.

Respondents were asked how well they would like a young man/ young woman of their own household to do the following things/ activities/ employments, on a scale ranging over five points.

\section{Case study results: factor analysis}

I used exploratory factor analysis after trying confirmatory factor analysis on groups of about 8 variables and getting nothing I could interpret. I inputted 35 variables excluding socio-demographic variables. If you set the eigenvalue minimum at 1 , about 8 or 9 factors would emerge, but I ultimately chose to analyse only the four most important factors since the others were similar to earlier, more powerful ones. I also used orthogonal rotation to get a clearer differentiation of the factors even though I had already worked out my interpretation of the first and second factors, and the rotation did not change this basic analysis much. However the rotation helped to clarify (by simplifying the strongly loaded components) my analysis of the third and fourth factors.

The four factors (each composed of a weighted sum of several Likert scale variables) that emerged were:

- Traditional rural labour market aspirations, e.g. young women or young men doing renting land for vegetables, agricultural labour, and similar.

- 'GIZ A JOB' aspirations for long term contracts, e.g. young men joining in medical job, learning information technology, or doing factory work.

- Desire to innovate and modernise, e.g. young women or young men learning sewing, English, and IT, and joining ChitFund

- Micro-business aspirations, e.g. young women buying livestock or having a printing business; young men buying livestock of having small or large livestock.

(Note: in some cases the general feeling was a negative one for the job or activity listed, but the factor component appears as a positive one, hiding the substance of the feeling about doing the thing. Low factor loadings imply low correlations with the factor, but high factor loadings imply either positive or negative correlation among the elements comprising the factor).

The interpretation offered here is based upon a many-tomany mapping between variables and 'things' (particular orientations which I have labelled aspirations for the moment), as illustrated in Diagram 1.

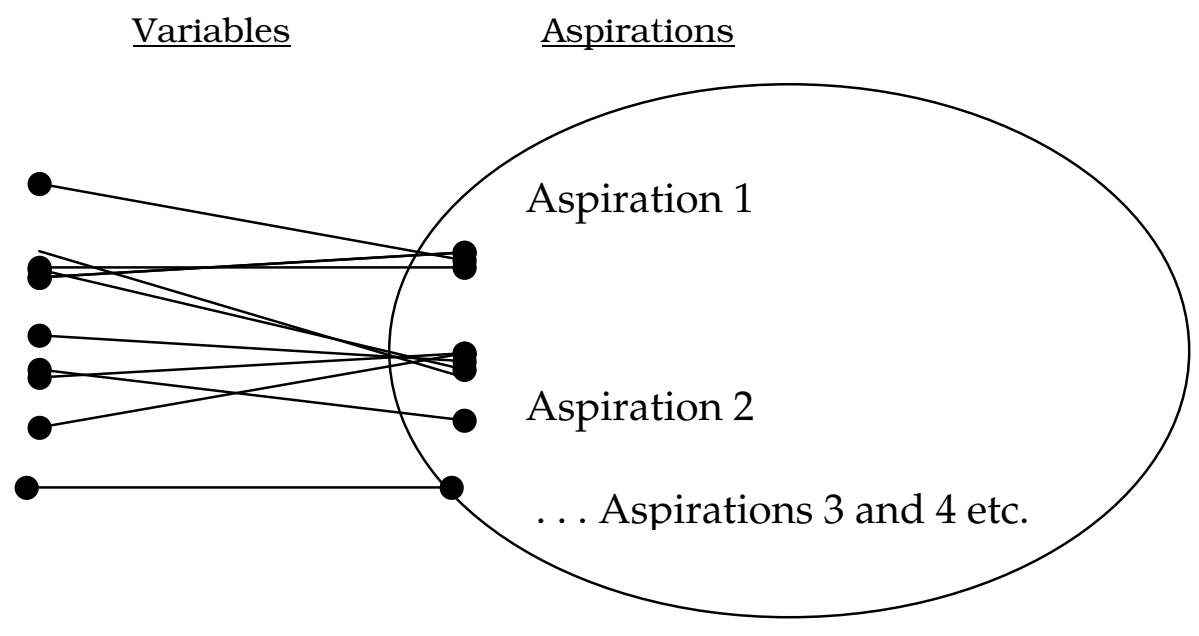

Diagram 1: A Many-to-Many Mapping 
This diagram illustrates the kind of complex result one may get from exploratory factor analysis. In my view it has many potential links with the methods of discourse analysis which are commonly used in qualitative data analysis. Rather than measuring the strengths of correlations and hence reliability of this way of labelling aspirations, perhaps at this stage one should look directly at texts and other sources of discursive evidence. Modifications may then need to be made - either to the discourse analysis or to the research instrument or to the interpretation that is being made.

For those who wish to review the details of the factor analysis results, a more lengthy presentation of the work, including appendices and detailed qualitative analysis, was presented in 2000 and can be obtained by internet (Olsen, 2000).

In summary, this factor analysis provides a way to reduce the complexity of the 35 variables to just four variables, each representing some form of aspirations but without being mutually exclusive of each other. Gender is muted in the factor analysis because the preference of some respondents for young men to do a particular job and young women not to do it is not visible here. Previous analysis, written up elsewhere, showed that the gender stereotyping was very strong, especially for the more enterprising occupations, across the sample. However casual agricultural work was seen as highly appropriate for women as well as men across all the poorer segments of the sample.

In the above analysis I have used SPSS data-reduction factor analysis options. AMOS and STATA, among others, offer the same results with different output formats. Both AMOS and STATA assume that latent-variable analysis will enable several variables to represent one concept, and ground this framework in Loehlin's text (Loehlin, 1992). Loehlin's treatment tends to confuse the latent variables with the thing which exists and is being represented. Loehlin treats the situation carefully, calling a model a 'measurement model' if it is merely meant to approximate the measurement of different characteristics of a single thing (latent variable models per se), and contrasting this with a 'causal model' which analyses the relations (expressed or measured as observed correlations) between different things, some of which are measured as latent variables (1992: 134-135). In the second case the phrase 'latent variable' is being used to refer to a thing which is hard to measure. The literature on factor analysis routinely problematises the dichotomy between observable and unobservable which has been central to debates about different variants on realism in the philosophy of science. What is often called 'unobservable', e.g. anger, aspirations, or beliefs, can be converted into crudely measured 'observations'. Instead of unobservables one often has merely unobserveds. Innovation in statistical science then consists partly in creating new measurement possibilities through new conceptualisations. Parsing one thing into many is the bread and butter of social statistics.

The conceptual work involved in distinguishing latent variables representing real, but unmeasurable (unmeasured?) things in society, is probably often idealised. However if these things really exist then their effects may be seen in the outcomes that result from them and/ or in proxies for their existence. Therefore it may be necessary to proceed from factor analysis to regression analysis (or path analysis) before beginning to be ready to accept, reject, or modify a proposed factor model. The realist retroductive approach would suggest that no firm conclusions can be drawn from factor analysis itself, but that further procedures can be appended to the factor analysis before conclusions about the real social things and their interconnections should be drawn.

\section{ALgORITHMS OR ROUTINES FOR FACTOR ANALYSIS AND REGRESSION ANALYSIS}

Regression analysis has three standard algorithms: entering all the variables at one time; entering them one by one according to which has the greater statistical significance, stopping once an acceptable level of significance cannot be achieved; and entering them all but using 'backward stepwise' decision making to remove variables. In all three cases statistical significance measures are the standard, widely accepted criterion for including or removing variables. Therefore the first algorithm is seen by many statisticians as rather ad hoc since the regression that gets published is the one the researchers choose to present, often without any remaining insignificant variables, rather than an all encompassing regression which would indeed bore many readers with unnecessary variables.

In textbooks, parsimony is often offered as another tactic to be interwoven with these basic algorithms, and in this context factor analysis appears as an ad hoc method of reducing the collinearity among a group of variables within a regression equation. The tendency to use factor analysis in a very ad hoc way is precisely what the present paper has constructively attacked. ${ }^{2}$ Instead, conceptual developments rooted in the literature survey, the qualitative analysis of talk and texts in the research arena itself, and even the ongoing lessons gleaned from the survey will sensibly improve the researcher's choice of variables and groupings - not arbitrarily. If critical realism is the overall underlying outlook then the process of factor analysis will proceed using a mixture of thought and statistics, regardless of whether the underlying sample is a random sample or not. However measures of statistical significance, such as the Chi-squared and degrees of freedom after doing factor analysis, have little importance in the critical realist approach.

Finally one must recognise that all statistical textbooks recommend that the researchers avoid omitted-variable bias. Statistical texts contradict themselves twice over: once by arguing for parsimony but against omittedvariable bias; and a second time, by arguing that any of the three mechanical algorithms first mentioned (enter-all; forward-stepwise; backward-stepwise) offer a neutral or objective way of choosing which variables to enter whilst at the same time arguing that the researcher tries to avoid omitted-variable bias by constructing a survey to include all the variables that one thinks will be relevant!

It has always seemed to me that enter-all algorithm would be the best one, even if some variables have 
insignificant effects, if one wants to examine the data in the light of a priori conceptualisations and hypotheses. The other two algorithms have the taint of empiricism: deriving truth claims from the data alone, i.e. from the sense impressions, with little attention to the actual events that have driven the collection/ creation of these data and to the real structures underlying both the conceptual debate that is going on and the actual events and empirical observations that occurred.

Factor analysis algorithms as presented in textbooks are less prescriptively set out than those for regression. To me this is a strength enabling factor analysis to be used in conjunction with qualitative data. But one person's factor analysis can easily be criticised by another person with a different conceptual framework (Freedman, 1987; Hope, 1987; and other papers in that volume). The debate was reviewed by Loehlin (1992) who proposes two algorithms: one is to choose the factor analysis technique to suit the conceptual framework one wants to impose on the data; the second is to use exploratory factor analysis to enable the data to 'show the researcher' a structure of relationships among variables that may be interpretable in connection with ongoing debates.

In the case study exploratory factor analysis of the Likert scales did indeed mesh with existing debates. In particular it seemed to show that there are traditional and modern or innovative approaches to labour markets, the latter being associated with taking risks and investing capital into business but especially human capital in business-related areas; and it suggested that there was not a grouping of attitudes either along a gender axis, nor along a formal/ informal labour market axis, nor along a youth-activity versus labour-market activity axis as the questionnaire tended to lead the respondents. In other words the real structure existing among labour-role attitudes (and especially labour-market role attitudes) tended to reveal itself with exploratory factor analysis. The algorithm used was principal-axis analysis with orthogonal rotation. I reconsidered the qualitative comments made by various respondents and written in English. (A longer paper with a report on the qualitative data was presented at the Conference of the European Association for Evolutionary Political Economy, Berlin, 2000; see eaepe.tuwien.ac.at for a copy.) Suddenly the four factors made sense. I also could not comprehend more than about four factors, but the computer highlighted 8 or 9 factors. Thus the structure of the social world in this mini-study is probably more complex than I am prepared to handle. That is generally true, but rarely admitted by social statisticians.

\section{Conclusion - Remarks ON The SuPPosed Firmness Of TRUTHS AMONG EMPIRICISTS}

In this paper I have reviewed a statistical procedure that is commonly used by statisticians: factor analysis. This procedure or set of procedures is seen to be part of statistical algorithms that form a crucial component of the statistical inference discourse. In this discourse random samples and representativeness are made into a fetish. Numerous researchers have poked holes in the 'truth' claims that result. For instance, Nelson reviews critiques of the notion that a researcher can be objective, or that objective truth can exist outside a researcher's own aims (Nelson, 1996). Aldridge (1993) argues that statistical texts pretend to be impersonal and thus achieve, through specific tricks of discourse, a pretence of objectivity that legitimises their claims. Others have ploughed the same furrow.

More constructively, though, the triangulation school aims to show that statistical data rest upon prior discourses embedded in qualitative and other research, usually referred to in the literature review section of scientific papers. This linkage, argue the proponents of triangulation, implies that qualitative analysis always underpins quantitative analysis and that the two are intrinsically linked, not separate (Bryman, 1988; Gilbert, 1993). A critical realist might go further and argue against the exclusion of outside evidence from the 'hermetically sealed' statistical data set. Survey data are best analysed in the context of other evidence, not in isolation. This 'context of other evidence' include the author's own experience, their understanding of the literature reviewed, their qualitative or pilot interviews, and their manipulation of the survey data set itself. People, tasks, markets, attitudes, anger, stereotypes - none of these are contained within any one survey data set. Instead, the data merely tap into the rich social world.

Only a simplistic methodologist would suggest that truth emerges from factor analysis. Similar simplifications underlie crude uses of falsification and traditional empiricist approaches to objectivity. A more pluralistic methodology will tend to require either the abandonment of objectivity or a 'strong objectivity' as suggested by Harding, in which prior assumptions and norms are specified and come within the remit of the research. The hermetic seal around a single data set must be broken. Four ways to break it are:

- focus on the ontological extension of things conceptually and in space \& time;

- recognise that theory and the foci of research arise outside the realm of 'facts';

- discuss the preferences revealed by the choice of hypothesis (Sen, 1980);

- appreciate that qualitative meanings are contested and overlapping.

The 'firm' realm of 'hard data', enclosed by its hermetic seal, ${ }^{3}$ should be contested.

The survey instrument itself can also be a source of innovative and empowering discussion if it is seen as not being reified and not being simply imposed from outside but developed through a process with insiders (Olsen, 1999). ${ }^{4}$

The procedures described in this paper represent moves toward a redefinition of the survey method as a set of creative and transformative activities with intended, but not fully pre-prescribed, outcomes. Such activities are actually human work, to be done either alone or in cooperation with others. This particular kind of work leads to informative re descriptions of the social world. The approach can be applied in both economics and sociology, 
and can be related to/ integrated with existing theory, but may lead to revision of theory. It challenges a new hegemony of social constructionism in sociology which is beginning to permeate development studies as well. I base my research on realism rather than phenomenology but don't 'throw out the baby with the bath water'.

It is wrong to dismiss statistical models just because they are unrealistic. Instead, critical realists can undertake a constructive project of re-working algorithms so that they are well informed, rather than statistical. Such a programme offers potential for a reinvigoration of critical statistics within triangulated research strategies.

\section{Notes}

1. I wish to acknowledge the research assistance of $\mathrm{J}$. Rangaswamy, Prasad Babu, and Devika, without whose help these data would not have been available. Rangaswamy and Prasad Babu assisted me in my PhD research in 1984-1988, for which period of fieldwork I gratefully acknowledge the financial support of the George Webb Medley Fund, the University of Manchester Department of Economics, the Marshall Foundation, the Nuffield Foundation and the Beinecke Fund. In addition Rangaswamy and Devika co-operated in conducting the revisit to a random sample of 80 households during 1999 and the creation of a survey data set based upon the pilot questionnaire. There are logistical problems in accessing people in their huts in remote villages but these experienced researchers made it possible.

2. Notice that in my exemplar I have focused mainly on the attitudes as outcomes $(\mathrm{Y})$, whereas in the regression literature factors are seen as simplified independent variables $(\mathrm{X})$ which reduce the complexity of causes. I hope to use factors in both ways, i.e. as intermediates.

3. Thanks to $S$. Walby for suggesting this term.

4. See J. Heron, 1996, Co-operative Inquiry: Research Into the Human Condition, Sage, London. And Olsen W. K. (1994) Researcher as Enabler: An Alternative Model for Research in Public Health, Critical Public Health, 5:3, 5-14.

\section{References}

Aldridge, J. (1993) The Textual Disembodiment of Knowledge in Research Account Writing. Sociology, 27(2), 53-66.

Bhaskar, Roy (1975) A Realist Theory of Science, Leeds Books
Ltd., repr. 1977 by Verso, London; new edition available from Verso, 1997.

Bryman, A. and Cramer, D. (1997) Quantitative Data Analysis With SPSS For Windows: A Guide for Social Scientists. London, Routledge.

Ehlers, T. and Main K. (1998) Women and the False Promise of Microenterprise. Gender and Society 12(4), August 424-440.

Freedman, D. (1987) As Others See Us: A Case Study in Path Analysis. Journal of Educational Statistics 12(2), 101-128.

Heron, J. (1996) Co-operative Inquiry: Research Into the Human Condition. Sage, London.

Hope, K. (1987) Barren Theory or Petty Craft: A Response to Professor Freedman. Journal of Educational Statistics 12(2), 129-147.

Lawson, T. (1997) Economics and Reality. London, Routledge.

Loehlin, John C. (1992) Latent Variable Models: An Introduction to Factor, Path, and Structural Analysis (2nd ed.). Lawrence Erlbaum and Assoc., NJ and London.

Nelson, J. (1996) Feminism, Objectivity and Economics. London, Routledge.

Olsen W. (1992) Random Samples and Repeat Surveys in South India, Chapter 4 in S Devereux and J Hoddinott, (eds.), Fieldwork in Developing Countries, Harvester Wheatsheaf, $57-72$.

Olsen W. (1993) Competition and Power in Rural Markets: A

Case Study from Andhra Pradesh. Bulletin of the Institute for Development Studies 24(3), June 83-89.

Olsen W. (1994) Researcher as Enabler: An Alternative Model for Research in Public Health. Critical Public Health 5(3), 5-14.

Olsen W. (1996) Rural Indian Social Relations, Oxford University Press, Delhi.

Olsen W. (1999). Path Analysis For the Study of Farming and Micro-Enterprise, Bradford Development Paper No. 3, Development and Project Planning Centre, University of Bradford. (available for $£ 7.50$ from B. Green, DPPC, Univ. of Bradford, BD7 1DP).

Olsen, W. (2000). Conference paper for the European Association for Evolutionary Political Economy, Berlin, available to members of EAEPE from http://eaepe.tuwien.ac.at

Olsen W. and DaCorta L. (1990) On the Road to Nimmanapalle: An Empirical Analysis of Labour Relations in Drought-Prone Villages in South India, Discussion Paper No. 66, Department of Economics, University of Manchester, March, 42

Sayer, A. (1992). Method in Social Science: A Realist Approach, (2nd ed.). London, Routledge and Kegan Paul.

Sen, A. (1980). Description As Choice. Oxford Economic Papers.

\section{Venkatraman Subramaniyam \\ Critical Realism and Development Programmes in Rural South India}

\section{INTRODUCTION}

Development programmes in India over the years have concentrated more on quantifiable endeavours like construction of buildings, roads, dams, distribution of medicines etc. However, there has been very little emphasis on issues that would bring about perceptible change in involvement of the community in the development efforts. This can only be achieved by raising awareness leading to behaviour change among the community, by making the community participate, use and demand services from the various development programmes. One reason for this slow progress in mobilising the community has been primarily the method adopted in planning and implementing of any programme, especially the ones that target women and children. The use of highly centralised and pre-determined approaches by the various donor agencies and government departments has led to such stagnation. Although any development initiative may in spirit aim at making the 